\title{
EL «ÚLTIMO» MacCORMICK: LA RAZÓN PRÁCTICA Y UNA NARRATIVA COHERENTE EN TORNO A LA SOBERANÍA POST-NACIONAL *
}

\author{
Joxerramon Bengoetxea ( $\mathrm{Ph} \mathrm{D,} \mathrm{Edinburgh)}$ \\ Universidad del País Vasco-Euskal Herriko Unibertsitatea
}

\begin{abstract}
«Sobrevalorar la vida puede llevar a un miedo desproporcionado e incluso supersticioso de la muerte. La muerte no es lo opuesto a la vida, sino su confín natural exterior... La muerte no es la negación de la vida sino, cuando llega en su momento, su consumación, y como tal, debería ser aceptada con gratitud. Es parte del Derecho natural, en su sentido sostenible, que la moralidad humana tiene conexiones reales con la mortalidad humana».
\end{abstract}

(N. MacCormick, Practical Reason in Law and Morality ${ }^{1}$ )

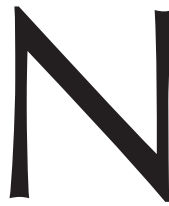

MACCORMick (Glasgow, 1941, Edinburgh, 2009) se nos ha ido tras una dolorosa enfermedad el 5 de abril de 2009. Nos ha dejado un rico legado escrito y el ejemplo de una vida buena, sabia y bien aprovechada ${ }^{2}$. Quienes tuvimos la fortuna de conocerle, además de leerle, compartiremos un recuerdo imborrable de su optimismo, su bondad y su genialidad. MACCORMick ha entrado ya en la Historia de la Filosofía 1) por su notoria contribución a la filosofía práctica contemporánea, entroncando con las tradiciones ilustradas escocesas (HUME y sobre todo SMITH), ensamblándolas con KANT, y aplicándolas a la teoría política y constitucional, y 2) por su desarrollo de la teoría institucional del Derecho y de su concepción hermenéutico-retórica, logrando compaginar la teoría analítica del Derecho con una versión del Derecho natural ${ }^{3}$.

* Fecha de recepción: 4 de febrero de 2010. Fecha de aceptación: 4 de febrero de 2010.

1 OUP, Oxford, 2008, pp. 208-209; en adelante Practical Reason. Las citas en castellano son mi propia traducción. En algún caso se ha añadido el original en inglés por miedo a perder importantes matices. Traducir a MACCORMICK es siempre arduo y osado y conviene acudir directamente a la versión original. Si traducirle es difícil, interpretarle es obra de titanes: él mismo solía comentar que era temido por el servicio de interpretación del Parlamento Europeo.

2 «La sensación de vivir por un tiempo limitado es uno de los incentivos que tenemos para ser diligentes y trabajadores. Pasamos por este camino sólo una vez, y si no lo aprovechamos, la pérdida y el fracaso serán sólo nuestros...», Practical Reason, p. 208.

3 Aquélla que, en un contexto socio-político y un nivel de desarrollo económico dados, perseguiría un bien común genuino y satisfaría las condiciones del imperativo catégórico smithiano, que explicaremos más adelante. Este giro naturalista sostenible se detecta especialmente en Institutions of Law (Oxford, 2007) y en Practical Reason (p. 202). 
La obra iusfilosófica de MACCORMICK es bastante conocida universalmente y gran parte de ella ha sido traducida a varios idiomas, entre ellos al español. Un repaso a sus ideas principales en lengua castellana puede encontrarse en la interesante y profunda entrevista que le hizo M. ATIENZA para Doxa y en mi propia contribución al Anuario de Filosofía del Derecho de 2010. En este homenaje necrológico — mitad biografía, mitad glosa - quisiera abordar otra parte fundamental de la obra y del pensamiento del genial pensador escocés, su legado moral y político y su contribución al pluralismo constitucional en torno a la Unión Europea, al Reino Unido y a Escocia.

Para ello, aportaré unos trazos biográficos entrelazados con recuerdos personales y citas directas de N. MACCORMICK (I) y esbozaré tres narrativas en torno a los temas que han dominado su pensamiento político y constitucional (II): una concepción de la persona y de los derechos humanos, una concepción del estado y el Derecho y una concepción de la soberanía y la democracia. Estos grandes topoi constitucionales se plasman sobre la integración europea y sobre las naciones, con o sin estado propio, que la conforman.

\section{LA PERSONA}

Neil era hijo del Dr. J. MacCormick, un abogado de Glasgow conocido como «King John», un líder del nacionalismo escocés más conocido como «perseguidor» pursuer o plaintiff) o demandante en el asunto «E II R» (MacCormick vs. The Lord Advocate, 1953), donde cuestionó la legalidad de título de la Reina para designarse como «Isabel Segunda» en Escocia, atendiendo que Isabel Primera no había sido nunca monarca escocesa sino inglesa. Con esta impresionante herencia, no sorprende que Neil se afiliara al SNP (Scottish National Party) ${ }^{5}$, partido que representó como candidato en cinco elecciones parlamentarias entre 1979 y 1997, o que se convirtiera en uno de los eurodiputados escoceses entre 1999 y 2004. Su hermano mayor, Iain, fue miembro del Parlamento británico por Argyll, representando al SNP entre 1974 y 1979. El nacionalismo de MACCORMICK, como veremos más adelante, no tiene nada de estrecho, xenófobo o anglófobo sino que era generoso y de amplitud de miras, inspirado por las mejores tradiciones de la Ilustración Escocesa y del «intelecto democrático», del que Neil era un claro exponente.

Neil nació el 27 de mayo de 1941, en Glasgow en una familia de dos hijos y dos hijas. Su madre aportaba al hogar el contrapunto estable a los entusiasmos caóticos de su padre, como los relatara el propio Neil en su prólogo a la reimpresión del libro de su padre de 1955 «The Flag in the Wind» ${ }^{6}$. Neil se educó en Glasgow High School y Glasgow University, donde obtuvo matrícula de honor en Inglés y Filosofía. Neil fue a

4 Doxa: Cuadernos de Filosofía del Derecho, núm. 29 (2006), pp. 479-489.

5 El Obituary que sir D. EDWARD le dedicó en The Guardian, «Fervent Scottish nationalist politician and distinguished legal philosopher» (7 de abril de 2009) me ha aportado valiosos comentarios aunque el epíteto de ferviente deba matizarse a la luz de la parte II de esta nota. Puede consultarse en: http://www.guardian.co.uk/ politics/2009/apr/07/obituary-sir-neil-maccormick.

${ }^{6}$ JoHn fue uno de los cuatro escoceses que recuperaron de la abadía de Westminster la Scottish Coronation Stone refugiándola en un lugar secreto, un día de Navidad de 1950, cuando Neil tenía nueve años. Este aspecto ha sido recientemente objeto de una película, Stone of Destiny, que los productores proyectaron especialmente para Neil y Flora en su hogar de Morningside, Edimburgo, la víspera de su estreno. Les acom- 
Inglaterra a estudiar Derecho inglés, en el Balliol College de Oxford. No llegó a estudiar Derecho escocés en Escocia aunque lo dominaba y conocía en profundidad. Fue admitido a la abogacía inglesa (barrister en el Inner Temple) en 1971 y se le concedió el rango honorífico Queen's Counsel en Inglaterra en 1999.

En su juventud también destacó en el rugby y en la gaita escocesa, instrumento que siguió tocando en múltiples y sorprendentes ocasiones, entre otras en la ceremonia del Congreso Mundial de la IVR ${ }^{7}$ en 1989 y en el funeral de su amigo y contrincante político, el líder laborista John Smith en la isla de Iona en 1994. En una ocasión pude presenciar un sprint francamente veloz en ropa de calle dentro del Old College: se le habían olvidado los exámenes (essays) de sus estudiantes en el Tea Room que entonces funcionaba junto a la galería Talbot Rice. Cuando le felicitamos por semejante proeza, nos bromeó que en el rugby se le daban mejor las carreras que los «ensayos». Respecto de la gaita, él mismo relata en su Practical Reason (p. 83), al tratar el concepto de tradición, que fueron dos de sus tíos abuelos, Neil y Dugald, ya ancianos, quienes le transmitieron, tatareándoselos, esos conocimientos musicales adquiridos por ellos en la lengua gaélica en los ceilidh (veladas de canciones, música instrumental, tertulia y danzas ocasionales) o en los juegos de Highland locales de un pueblo de las Hébridas a finales del siglo XIX.

MacCormick fue discípulo de H. L. A. HART, posiblemente su influencia teórica más evidente y sobre quien escribió una importante obra, H. L. A. Hart, (Stanford, 1981) cuya reciente segunda edición (Stanford, 2008) tuvo en cuenta el famoso Postscript de la segunda edición póstuma del Concept of Law (Oxford, 1994) en el que HART esbozó una respuesta a las críticas formuladas por su sucesor en la cátedra de Jurisprudence, R. Dworkin. Esta segunda edición de H. L. A. Hart nos permite entrever un MACCORMICK post-positivista, algo más distanciado de su maestro. En la página 15 de esta segunda edición nos relata cómo HART le reprochó haberle presentado en su libro como más ius-naturalista de lo que le gustaría ser.

La contribución de MACCORMICK a la filosofía del Derecho, moral y política se traduce en numerosas y valiosas publicaciones en lengua inglesa y traducciones a varios idiomas, en su constante contribución a la IVR que presidiera hasta su fallecimiento fruto de un cáncer intestinal incurable, y se complementa con una acción práctica como personaje político al ser miembro destacado del SNP, eurodiputado por Escocia (entre los años 1999-2004), miembro alterno de la Convención sobre el futuro de Europa (2002-2004), asesor para asuntos europeos del First Minister del ejecutivo escocés (2007-2009) y referente ideológico de las naciones europeas sin estado propio (dentro del grupo político europeo Alianza Libre Europea). MACCORMICK concebía la política como una virtud entrelazada con lo público o comunal:

«Para mantener las instituciones de una comunidad próspera se necesita la política, y el tipo de política necesaria para mantener tales instituciones entre personas moralmente

\footnotetext{
pañaban I. HAMILTON, autor de Stone of Destiny (Edinburgh, Birlinn, 2008) y uno de los cuatro implicados en la escapade, y su esposa Jeannette (Practical Reason, p. 203).

7 Asociación Internacional de Filosofía Jurídica y Social, que organiza Congresos Mundiales los años impares. El Congreso Mundial de 1989 fue organizado en Edimburgo por un Comité dirigido por N. MACCORMICK y tuvo como título «Ilustración, Derechos y Revoluciones», premonitorio de los cambios que transformarían Europa Central, la antigua Unión Soviética y todo el mundo, a las pocas semanas de celebrarse dicho Congreso, con la caída del Muro de Berlín.
} 
autónomas es la política democrática en un estado constitucional y democrático. Es una parte esencial del bien humano el buscar algún tipo de implicación con el auto-gobierno de su propia sociedad sea a través de un cargo electo, sea a través del activismo político a nivel local, provincial o central - $\mathrm{O}$ incluso europeo, dentro de la UE— sea a través de grupos de presión, ONGs o del compromiso con causas concretas, o sea a través de alguna otra manifestación de la sociedad civil. Hay una profesionalización creciente de la política en las sociedades occidentales que amenaza el buen funcionamiento del cuerpo político. La ciudadanía comprometida es la savia de una polis saludable. Ser ciudadano comprometido y activo es vivir bien y contribuir al bienestar de la comunidad. Sin duda alguna hay políticos henchidos de su propia importancia, otros se corrompen y otros presentan concepciones desviadas del bien común y de la justicia. Pero en los intercambios vigorosos del debate democrático, apoyado por medios de comunicación libres y honrados (algo que lamentablemente falla en gran parte de la prensa contemporánea) surge una verdadera oportunidad de que aflore la verdad. La mera existencia del debate y de los alegatos es una garantía contra la osificación y la parálisis». (Practical Reason, p. 166).

Además de su compromiso político, MACCORMICK asumió numerosos empeños universitarios tanto de estudiante —llegó a ser dirigente de la Oxford (students') Union - como de profesor - muchos años decano de la facultad de Derecho, «provost» de las ciencias sociales y jurídicas, y «vice-principal» de la Universidad de EdimburgoDestacó como excelente administrador, algo que no siempre se suele esperar de los ius-filósofos, sin duda erróneamente, sobre todo respecto de quienes tienen formación analítica. Su carrera académica está estrechamente ligada a la cátedra regia de Derecho Público, Natural y de las Naciones creada en 1707 (el año de la Unión de los Parlamentos) en dicha Universidad, a la que accedió a la temprana edad de 31 años tras un breve periplo por las universidades de Saint Andrew's (Queen's College, Dundee) y Oxford (Balliol College). MACCORMiCK era miembro activo de la Royal Society of Edinburgh (vice-presidente entre 1991-04; Medalla Real en 2004) y de la British Academy donde impartió la Conferencia Jurídica de 2006 con el título «Judicial Independence: Who Cares?» (desde luego a él le importaba, y mucho) así como miembro de la Academia Finlandesa de las Ciencias. Constantemente recibía invitaciones para ser profesor visitante en universidades de todo el mundo y fue investido de al menos seis doctorados bonoris causa. Tuve la suerte de presenciar una de las ceremonias en la Universidad de Saarbrücken, apadrinado por H. Jung. El discurso de MACCORMICK tuvo por título: «Can Judges Make Mistakes?» al cual añadía la coletilla: ¿y cómo lo sabríamos nosotros?

A pesar de su influencia mundial MACCORMICK nunca creó escuela, ni pretendió hacerlo. Sus colegas en el Centre for Criminology and the Sociological and Philosophical Study of Law (CCSPSL, ahora Centre for Law and Society), sus doctorandos, seguían sus propios intereses. De hecho le interesaba más fomentar la crítica o enfoques alternativos que impulsar tesis y trabajos ceñidos a sus propias teorías. Dicho esto, conviene sin embargo añadir que MACCORMICK era un co-autor muy interactivo, interesado siempre en captar la visión de su interlocutor y de llevarla un paso adelante. Su edición de la obra póstuma de J. WróBLEWSKI, su coautoría con P. AMSELEK, O. WEINBERGER, R. Summers o Z. BANKOWSKI ${ }^{8}$, por ejemplo, indican dos virtudes excepcionales y escasas dentro de la filosofía jurídica anglófona: un empeño por desarrollar visiones y

8 ZENON ha sido otro de los apoyos constantes de MACCORMICK, en lo personal, en lo académico y en lo intelectual. El impacto de BANKOWSKI sobre Practical Reason es sutil, pero decisivo. 
discursos colectivos y una apertura a, y difusión de, pensadores que han publicado sus obras en idiomas distintos del inglés?

Sus numerosas co-autorías de trabajos y libros y su co-edición de compilaciones y obras colectivas son buena prueba de ese singular empeño por un pensamiento discursivo y dialógico. También en sus escritos individuales MACCORMICK está en constante interacción con otros autores, pero no con la finalidad de vencer en una confrontación dialéctica de ideas sino buscando matices, aproximaciones, nuevos matices de síntesis y consenso sin mermar en coherencia argumental ni caer en sincretismos, y sin miedo a recular cuando consideraba que había errado. Este empeño por alcanzar el consenso sin caer en el sincretismo lo practicaba no sólo en sus diálogos y discusiones grupales sino en sus propios escritos. Una muestra genial de esta práctica la encontramos en su propuesta ética ${ }^{10}$ del imperativo categórico smithiano:

«"Entra tan plenamente como puedas en los sentimientos de toda persona implicada o afectada por un incidente o por una relación, y fórmate imparcialmente una máxima de juicio sobre cuál sea la acción correcta que todos podrían aceptar si se comprometieran a mantener creencias mutuas que fijasen una medida de aprobación o desaprobación común entre ellos".

Esto conduce a un imperativo subsidiario:

"Actúa de acuerdo con esa máxima de juicio imparcial sobre cuál sea la acción correcta respecto del incidente o de la relación en cuestión”».

Por su impresionante carrera universitaria y su contribución al pensamiento jurídico fue investido Sir en 2001. Además de excelente político ${ }^{11}$, dedicado investigador y prolífico autor, MACCORMICK era un excelente profesor y conferenciante y dedicaba gran parte de su tiempo y de su atención a sus estudiantes y colegas consiguiendo que los estudios de Jurisprudence en Edinburgh se convirtieran en un centro de reputación mundial y de atracción de estudiantes de postgrado y de académicos.

Neil contrajo matrimonio con Flora Milne (Britain) en 1992. Flora ha sido un apoyo constante y una infatigable compañera de faenas en el Parlamento Europeo; además de acompañarle y animarle durante su enfermedad. Además de Flora y de sus tres hijas nacidas de su primer matrimonio, Neil contaba con otro don precioso: un optimismo vital, inagotable hasta los últimos días de su dolorosa enfermedad ${ }^{12}$, su contagiosa

9 Esta apertura le llevó a impulsar y traducir, con R. ADLER, el clásico de R. ALEXY, A Theory of Legal Argumentation, Oxford, Clarendon Press, 1988. Fue Neil quien introdujo a Alexy en el mundo anglófono. Neil discutía en sus seminarios de 1987-88 los borradores de la traducción profundizando en las ideas de ALEXY. Curiosamente ambos darían luego un giro «naturalista» a lo RADBRUCH.

${ }^{10}$ Esta síntesis de KANT y A. SMITH la formula en al menos cuatro ocasiones en su Practical Reason (pp. 64, 76, 97-98 y 178) del modo siguiente: "Enter as fully as you can into the feelings of everyone directly involved in or affected by an incident or relationship, and impartially form a maxim of judgment about what is right that all could accept if they were committed to maintaining mutual beliefs setting a common standard of approval and disapproval among themselves".

That then leads on to a subsidiary imperative:

"Act in accordance with that impartial judgment of what is right to do in respect of the given incident or relationship"».

${ }^{11}$ Fue nombrado el mejor eurodiputado del año, en los premios de los mejores políticos escoceses en nada menos que tres de sus cinco años de mandato.

12 En la p. 92 de su Practical Reason, al analizar la autonomía moral explica lo siguiente: «Por ejemplo, yo he reducido mi peso, no por una decisión de tomarme mi salud más en serio o de controlar más lo que como y bebo, sino porque una enfermedad me impide tragar (gran parte de) mi comida. En un sentido es bueno que 
energía, su aptitud para ver siempre lo mejor de sus interlocutores, su integridad y honestidad, su carácter amable, afable, su sentido del humor, su chispa e ingenio, su inagotable capacidad de autocrítica, su sinceridad y transparencia son virtudes morales y estéticas que se perciben claramente en su obra. Por ejemplo, su Practical Reason, escrito durante sus últimos meses de vida, contiene interesantes reflexiones biográficas y personales, algunas de las cuales traemos a colación en esta nota. Una de ellas, «A real choice» ${ }^{13}$ se sitúa en una parte fundamental de su vida, cuando decidió retornar a la vida académica tras su exitoso periplo por el Parlamento Europeo y en ella explica las distintas consideraciones que estuvo sopesando a favor y en contra de las opciones alternativas que se le ofrecían: presentarse una segunda vez como candidato a eurodiputado con una alta probabilidad de ser reelegido o volver a la academia, a su Universidad de Edimburgo. Dejémosle hablar a él:

«Finalmente, cuando se trató de adoptar la decisión correcta sobre cómo pasar el último periodo de mi vida activa, me decidí por dar prioridad a las virtudes escolásticas [cuyo valor dominante es el de la verdad entendida como adecuada comprensión de un ámbito concreto de indagación], manteniendo mi compromiso político, en un plano subsidiario y sin por ello menospreciar las virtudes políticas [cuyo valor principal es la búsqueda de la justicia en la sociedad según una concepción de la justicia y del bien común] (...).

Así es como, en un modo autobiográfico, caracterizo actualmente la decisión que adopté en 2003 y cuyas consecuencias sigo percibiendo, dicho sea de paso, muy felizmente. En cierto modo, las grandes decisiones que uno adopta expresan un compromiso con aspectos del buen vivir, con las virtudes. Hay distintos modos (virtuosos) de vida que exhiben virtudes genuinas pero diversas, y uno debe escoger en función de su propio carácter y preferencias. Las elecciones que uno hace a lo largo del tiempo tienen un efecto conformador del carácter. Uno deviene en lo que hace. Lamentablemente, lo mismo ocurre con los modos viciosos de vida».

En resumen, la obra, teórica y práctica, de MACCORMICK constituye la mejor refutación posible a los despiadados ataques formulados desde posturas críticas y anti-analíticas como la de A. C. Hutchinson, para quien los teóricos del Derecho deben actuar localmente, interesarse por el poder ${ }^{14}$, abandonar la teoría y la ambición metafísica a decir algo trascendente y verdadero sobre el mundo jurídico válido en todas las sociedades y en todo momento (MACCORMicK lo dice y con fundamento) y convertirse a la genealogía mostrando la filiación política de las pretensiones jurídicas (MACCORMICK identifica perfectamente las fuentes filosóficas de inspiración de su pensamiento jurídico) y actuar localmente pensando en lo que mejor funciona para su propia sociedad (una preocupación constante de MACCORMICK) ${ }^{15}$. La vida de

pierda peso y tenga mejor forma física. Pero no merezco ningún crédito moral por hacerlo. Mi voluntad no ha estado implicada en ello». Evidentemente estaba teorizando con admirable distanciamiento smithiano sobre el cáncer de estómago que acabaría con su vida.

${ }_{13} \mathrm{Pp} .38$ a 43.

14 ¿Dejar a un lado quizás las reflexiones sobre los caracoles putrefactos en las botellas opacas de cerveza de jengibre, aunque contribuyan a desarrollar el Derecho de la responsabilidad civil? El asunto Donoghue vs. Stevenson es analizado brillantemente a lo largo de casi todas las obras de MACCORMICK, vid, , entre otros, Legal Reasoning and Legal Theory (Oxford, 2. ${ }^{a}$ ed., 1994), Rhetoric and the Rule of Law (Oxford, 2005, pp. 152-61) y también en Practical Reason (pp. 181-91). Por cierto, un color de botella similar se usa para comercializar el Buckfast Tonic Wine, que ya tuvo éxito como tonificante en la época de los hechos de Donoghue pero que causa estragos en la Escocia actual.

15 The Province of Jurisprudence Democratized, Oxford, OUP, 2009; es interesante observar que HuTCHINSON no menciona a MACCORMICK — de hecho no lo cita en absoluto- como exponente de la teoría 
MacCormick es un compendio de las virtudes auxiliares que, en su Practical Reason (p. 156), considera como disposiciones del carácter que le inclinan a uno hacia los objetivos valiosos y le ayudan a alcanzarlos: «integridad e independencia de criterio, auto-conocimiento, coraje, razonabilidad (o prudencia), competencia tecnológica, consideración hacia el prójimo, buenos modales, auto-respeto sin llegar al egoísmo, diligencia y voluntad para trabajar duro, junto con la paciencia ante la adversidad y la mala fortuna».

\section{TRES NARRATIVAS CONSTITUCIONALES SOBRE EUROPA (Y ESCOCIA)}

«El propósito central de los cuatro libros de la serie Law, State and Practical Reason ${ }^{16}$ es dar una explicación del Derecho como ordenamiento normativo institucional, uno de los elementos destacados de la auto-organización de los Estados. Pero también he insistido en que el ordenamiento normativo institucional, esto es, el Derecho, caracteriza no sólo a los estados sino también a otras formas de orden social y político entre los seres humanos. El Derecho estatal es un tipo de Derecho particularmente importante, pero no el único. Contemplamos típicamente a los estados como entidades dotadas de soberanía, y la soberanía se suele considerar esencial para la democracia y para el Derecho. Pero en el mundo contemporáneo, la soberanía multi-función y omnicompetente de los estados viene cuestionada. Especialmente en Europa parece muy dudoso atribuir una soberanía omnicompetente a cualquier Estado miembro de la Unión Europea. Por otra parte, sería exagerado pensar que la UE ha reemplazado a sus miembros como una especie de federación soberana o superestado. Podría discutirse entre los europeos amantes de la democracia si esta evolución sería bienvenida o preocupante y alarmante. Si el Derecho depende de que siempre exista un legislador (law-giver), habría motivos para preocuparse: la pérdida de soberanía equivaldría a una pérdida de derecho o de la propia autoridad final creadora de derecho. Sin embargo, para la teoría institucional del Derecho este argumento de la soberanía reposa sobre un error categórico que consiste en asumir que la creación de normas (norm-giving) precede al uso de las normas (norm-using)» (Practical Reason, p. 193).

Sobre esta larga cita, podemos glosar varios de los temas o narrativas que se siguen de una teoría institucional del Derecho desvinculada conceptualmente tanto del Estado como de la soberanía legislativa omnipotente:

1. Para empezar nos encontramos con la Unión Europea y su Derecho, un ámbito donde aparecen diversas soberanías constitucionales (supranacionalidad-intergubernamentalidad-interparlamentarismo).

2. En segundo lugar, nos encontramos con el Derecho y las formas de soberanía infraestatal y con el tema de la subsidiariedad y las versiones liberales del nacionalismo (la cuestión de la independencia de Escocia en Europa). El resultado es una pluralidad de órdenes normativos institucionales, lo cual nos lleva al debate sobre el pluralismo

\footnotetext{
jurídica objeto de sus filípicas; seguramente no por desconocimiento sino deliberadamente por ser un excelente contraejemplo que descalabra todo su edificio crítico antifundacionalista.

16 MACCORMicK se está refiriendo aquí a sus libros: Questioning Sovereignty: Law, State and Nation in the European Commonwealth (1999), Rhetoric and the Rule of Law: A Theory of Legal Reasoning (2005), Institutions of Law: An Essay in Legal Theory (2007) y Practical Reason in Law and Morality (2008), todos ellos publicados por Oxford University Press con forros de distintos colores: azul, rojo, morado y verde, como le gustaba recordar a Neil.
} 
constitucional ${ }^{17}$. ¿Existe una coordinación de los distintos sistemas (constitucionalismo multi-nivel) y sobre qué criterios, jerárquicos o heterárquicos? Podría decirse que la constitución de un ente concreto pueda ser representada como brote subordinado de un orden constitucional superior? ¿Cuál podría ser dicho orden?

3. En la medida en que nos pronunciemos por un orden supra-estatal de la protección de los derechos humanos como el que existe en Europa (control último por el Tribunal Europeo de Derechos Humanos), podremos entroncar con la concepción pluralista y post-positivista del Derecho, respetuoso con esa versión del Derecho natural plausible que defiende MACCORMICK.

La teoría institucional del Derecho y el concepto de razón práctica forman el hilo conductor o marco coherente de la triple narrativa que proponemos, inspirada en su libro Questioning Sovereignty, actualizado en su artículo «Questioning Post-Sovereignty» ${ }^{18}$, que es una recensión del libro de N. WaLkeR (ed), Sovereignty in Transition (Oxford, 2003). En las siguientes páginas desarrollamos estas tres glosas.

1. El concepto de «soberanía» debe desligarse del de «soberano», que puede corresponder a una persona, una institución, o una agencia que dentro de un territorio delimitado detentan o pretenden detentar un poder político, una autoridad jurídica, y/o una legitimidad moral lógicamente independientes de, y sin ningún tipo de delegación de, ni de subordinación a, cualquier otro poder, autoridad o legitimidad y lo ejercen sobre las personas que se encuentran en dicho territorio. Los Estados soberanos son independientes, en su territorio, de todo control político, jurídico (o moral) ejercido por otros Estados. Pero con el concepto de soberanía popular, ya no es necesaria la existencia de un «soberano», persona o institución, que asegure una soberanía única: los pueblos soberanos controlan la constitución de su polis y los poderes ejecutivo, legislativo y judicial se atribuyen a agencias distintas, contrapesando y controlando sus poderes. En las entidades más complejas, las formas de gobierno federal o cuasifederal proceden también a una distribución de las competencias entre los distintos niveles territoriales, sin que exista ningún «soberano», ninguna institución o persona que ejerza ningún poder ilimitado. Puede haber soberanía difusa sin soberano único.

Tomando como marco de referencia la Unión o, como a veces le gusta llamarla, Commonwealth Europea, MACCORMICK se ubica en las teorías post-soberanistas, críticas con el concepto dominante de soberanía, lo cual no excluye que existan aspectos de la soberanía que sigan teniendo vigencia. Los Estados post-soberanos mantienen aquellos aspectos de la soberanía clásica —legislativa, ejecutiva y judicial— que les es posible ejercitar, ya que existen límites tanto políticos como jurídicos dentro de los cuales se ha de ejercer la competencia estatal (vid. infra 3). Al haber abandonado algunos aspectos clásicos de la soberanía como poder ilimitado, único, indivisible han contribuido a crear las condiciones que favorecen la paz y la prosperidad, sin por ello

17 Como explica NergeluUs, The Constitutional Dilemma of the European Union, Groningen, Europa Law Publishing, 2009 (p. 36), el concepto de pluralismo constitucional lo lanzó MACCormick en su Questioning Sovereignty (incluso antes, con su artículo «Beyond the Sovereign State», Modern Law Review, 56, 1993, 1-18) donde lo analizaba como una version especial de pluralismo jurídico o coexistencia genuina de ordenamientos jurídicos institucionales. La idea la han adoptado posteriormente su sucesor en la cátedra de Edimburgo, N. WALKER, «The Idea of Constitutional Pluralism», MLR, 2002, pp. 317-359, y M. POIARES MADURO, A Constitução Plural, Cascais, 2006.

18 European Law Review, 2004, 29(6), 852-863. 
haber transferido esos aspectos a la Unión. La cuestión es si al compartir su soberanía en la Unión - bien sea a través de instituciones supranacionales comunes, bien a través de sus gobiernos reunidos en el consejo- han claudicado elementos esenciales de la misma de forma que se considere que han perdido ya su condición de soberanos, pasando dicha condición al ente superior y convirtiéndose los Estados en sub-sistemas de un sistema soberano (supranacional) o si es posible una confederación «soberana» (intergubernamental, inter-parlamentaria, pero también supranacional) de entes estatales post-soberanos.

Si nos deshacemos de las concepciones voluntaristas del Derecho (los mandatos de un único soberano) para abrazar concepciones más institucionalistas (pluralidad de genuinos ordenamientos normativos), podemos concebir sistemas solapados o reticulares sin relaciones jerárquicas, aunque serán necesarios criterios delimitadores y alguna forma de resolución de los contenciosos competenciales, lo cual requerirá voluntad y habilidad políticas, pero sobre todo un diseño institucional adecuado, como lo es el Derecho de la Unión Europea: atribución de competencias, primacía o supremacía, efecto directo, subsidiariedad e interpretación por el Tribunal de Justicia. Mientras tanto, los Estados miembros mantienen sus ordenamientos jurídicos constitucionales, en virtud de las enmiendas constitucionales realizadas, en su caso, para facilitar la puesta en común no sólo de las competencias atribuidas y el acquis sino también de las decisiones judiciales sobre tales atribuciones. La validez constitucional de los Estados miembros no proviene de ningún acto de reconocimiento de la Unión, sino que los pueblos de dichos Estados son soberanos para modificar su constitución como estimen oportuno, o incluso retirarse de la Unión. Sería muy difícil argumentar que existe un «pan-demos» de Europa que comprenda la totalidad de su ciudadanía, menos aún un soberano, persona o institución. Más creíble resulta una Unión supranacional, pero también intergubernamental, interparlamentaria y trans-judicial de distintos demoi post-soberanos. La democracia parlamentaria, en concreto se puede y se debe manifestar en todos los niveles donde se manifiesta la soberanía, para evitar que las instituciones burocráticas supranacionales y las intergubernamentales escapen del necesario debate y control parlamentario ${ }^{19}$. Ello exigirá una coordinación de todos los parlamentos y parlamentarios, representantes electos de los pueblos o naciones, una demoicracia deliberativa transnacional.

2. La transformación de los Estados post-soberanos no sólo se produce por su participación en entes supra-estatales e intergubernamentales dotados de su propio ordenamiento normativo institucional, sino también por la existencia de entes infraestatales pre-soberanos o cuasi-soberanos que comparten importantes aspectos de su competencia en la entidad superior que es el Estado miembro de la UE pero que también pueden, bajo ciertas circunstancias, desplegar sus competencias directamente en esa entidad supra-estatal poli-céntrica, poli-sistémica y multinivel que es la UE ${ }^{20}$. Entre los ordenamientos infra-estatal, estatal y supra-estatal se produce una cierta coordinación, en virtud del principio de competencia, de forma que nos encontramos ante

19 Sin llegar necesariamente a las prevenciones nacionalistas del Tribunal Constitucional Federal alemán en su sentencia sobre el Tratado de Lisboa, disponible en castellano en http://www.cepc.es/include_mav/ getfile.asp? IdFileImage $=3766$.

20 Questioning Sovereignty, 105. 
una diversidad o una pluralidad de ordenamientos, o a lo sumo ante un pluralismo constitucional institucional. No ocurre lo mismo con la co-existencia, dentro de un territorio no necesariamente coincidente con el oficialmente demarcado, de fenómenos normativo-jurídicos, o incluso ordenamientos normativos con cierto grado institucional. En estos casos nos encontramos ante un genuino pluralismo jurídico, donde distintos derechos aspiran a regular en el mismo territorio (importantes aspectos de) la conducta de las personas afectadas.

Concibiendo el Derecho — ordenamiento normativo institucional— como conceptualmente independiente del Estado podemos asumir un pluralismo jurídico y concibiendo la soberanía como algo que se puede compartir, resultando en redes heterárquicas, podemos asumir un pluralismo constitucional. Puede haber soberanía difusa sin soberano único y puede haber fenómenos jurídicos distintos dentro de un territorio, aunque uno de ellos pueda, ulteriormente, imponerse por la vía judicial.

Pero estas posiciones chocan frecuentemente con las pretensiones políticas que coligan soberanía y soberano. Así, pretender que un ente infra-estatal, Escocia por ejemplo, pueda considerarse soberano y considerar que comparte su soberanía dentro del Reino Unido y también simultánea e indirectamente dentro de la Unión Europea, parece chocar con los discursos clásicos de la soberanía. Pretender, más allá de estas interpretaciones jurídico-constitucionales, que los entes infra-estatales, o incluso los estatales, son naciones y que por ello, por su carácter de nación, detentan una soberanía originaria es adoptar una posición nacionalista.

Se refiera a naciones con su Estado propio (Estado-nación), o a naciones sin su Estado propio (¿región-nación?), el nacionalismo postula dos pretensiones importantes de la razón práctica: i) la nación es un valor ético-político, y ii) la soberanía popular que reside en la nación implica un poder constituyente, un demos, que puede expresarse de distintas maneras, creando un Estado propio, participando en Uniones o Confederaciones, en Commonwealths, o en entes supra-estatales ${ }^{21}$. Los entes plurinacionales que han adoptado una noción difusa de la soberanía han desarrollado herramientas y mecanismos adecuados, por muy contenciosos que resulten, para resolver las tensiones que puedan surgir por las pretensiones de las naciones que los componen. La propia auto-comprensión del ente y de sus componentes como plurinacionales y detentadores conjuntos de una soberanía difusa y compartida, o la división de competencias o la subsidiariedad y proporcionalidad son algunas de esas herramientas. Puede resultar, sin embargo, que las aspiraciones nacionales vayan más allá de estas fórmulas y deseen obtener el estatus de Estados miembros (post-soberanos) de la UE; en ese caso optarán por la independencia o más propiamente, la secesión, respecto del Estado plurinacional en que se encuentran para optar por la estatalidad propia y por la participación

21 En la versión liberal o defendible de nacionalismo de MACCORMICK, i) la nación es un valor prima-facie, no un valor absoluto, y ii) la soberanía es difusa y se puede compartir, sin necesidad de postular la existencia de un soberano único. El concepto de nacionalismo liberal lo han desarrollado Y. TAMIR, Liberal Nationalism, Princeton, 1993, o J. BengoetXeA, La Europa Peter Pan. El constitucionalismo europeo en la encrucijada, Oñati, 2005, además de MACCORMicK, ya desde Legal Right and Social Democracy, Oxford, 1982; vid. también su «Is Nationalism Philosophically Credible?», en W. TwINING (ed.), Issues of Self-Determination, Aberdeen, 1990, y sobre todo su capítulo 11 de Questioning Sovereignty, op. cit., «A Kind of Nationalism». En definitiva, postulamos un «nacionalismo sin fronteras», liberal y post-soberano. 
directa en el ente supra-estatal ${ }^{22}$. En este caso, la pregunta es quién decide sobre ese paso tan fundamental, ¿quién es el pueblo soberano, el demos: el ente estatal o el infraestatal?

«Si hay un significado de la soberanía popular (la soberanía como auto-determinación; quizá) que exige el reconocimiento de los derechos de grupos o comunidades significativos dentro de complejos más amplios, la versión estatal de la soberanía popular puede ser un enemigo de otros derechos democráticos. En general, toda forma de gobierno popular o de democracia mayoritaria plantea inevitablemente las preguntas: ¿quiénes forman el pueblo?, ¿de qué grupo debe la mayoría ser una mayoría?» (Questioning Sovereignty, 134)

Cuando la respuesta a estas preguntas se confía a una mayoría que pueda decidir sobre los confines del grupo (demos), o a un tribunal que interpreta una constitución en el sentido de que niega la consideración de demos a comunidades significativas dentro del grupo mayor, la minoría podrá verse permanentemente privada de su status de demos en un territorio que la mayoría define como parte de su propio todo.

Lógicamente si los postulados nacionalistas son: i) el valor absoluto de la nación, y ii) la imposibilidad de ceder o compartir soberanía, todos estos experimentos plurinacionales y post-soberanos resultarán impracticables e inaceptables; aparecerán posturas contrarias a la devolución o a la independencia de Escocia o contrarias a la posibilidad de que Escocia participe en el Reino Unido compartiendo su soberanía o contrarias a la primacía del Derecho de la Unión Europea sobre la soberanía de la Reina en el Parlamento. La mala prensa, en gran parte merecida, del nacionalismo, tiene que ver con el postulado del valor moral absoluto y sus corolarios prácticos: xenofobia, racismo, dominación de otros pueblos, etcétera. Además allí donde la democracia ha fracasado y la dictadura de un único partido se ha impuesto, la retórica nacionalista a menudo ha apoyado ideológicamente a la dictadura, a través de la victimización o de la demonización de las minorías ideológicas o nacionales ${ }^{23}$.

Pero partiendo de posiciones a la vez individualistas y universalistas alejadas de las concepciones atomistas y contractualistas de la sociedad caben versiones liberales y social-demócratas que postulan el nacionalismo cívico ${ }^{24}$ como un moral valor a compaginar con otros valores como la solidaridad entre los pueblos más allá de las fronteras nacionales, y en general viene limitado por los derechos humanos:

«El principio según el cual las naciones tienen derecho a (are entitled to) sus propios órganos de auto-gobierno no puede llegar a justificar arreglos que pongan en peligro los derechos fundamentales sea de los propios ciudadanos, sea de extranjeros, ni puede justificar el recurso a la violencia o a la acción inconstitucional. Es mejor sufrir el mal que infligirlo. Un recurso paciente a todas las vías constitucionales de mejora, incluso dentro de arreglos constitucionales imperfectamente justos o democráticos, tiene más visos de llevar a resultados satisfactorios a largo plazo que medidas aparentemente más expeditivas pero más crudas. Esas medidas casi irremediablemente rompen el tejido de la sociedad

${ }^{22}$ La influencia de MACCORMICK en la estrategia del actual gobierno escocés del SNP es innegable. Vid. A National Conversation (http://www.scotland.gov.uk/Topics/a-national-conversation) y el Libro Blanco de la propuesta de ley de referéndum presentada por el ejecutivo al Parlamento escocés el 30 de noviembre de 2009. La celebración del referéndum se prevé para noviembre de 2010. Compárese con la propuesta de la Comisión Calman para la mejora del autogobierno (devolution) en Escocia, http://www.commissiononscottishdevolution.org.uk/.

${ }^{23}$ Questioning Sovereignty, 168.

${ }^{24}$ HABERMAS ha propuesto el término Verfassungspatriotismus con connotaciones distintas. 
que pretenden servir. La historia del progreso que escoceses y galeses han logrado hacia la auto-determinación, con una casi total ausencia de violencia interpersonal, indica lo que es posible, como lo indica también el ejemplo sorprendente del "divorcio de terciopelo" entre Checos y Eslovacos hace unos años» (Questioning Sovereignty, 198)

3. Esta última observación nos presenta los derechos fundamentales como límite de todo nacionalismo defendible, en realidad de toda concepción normativa defendible. En el pluralismo constitucional, el pluralismo bajo el Derecho internacional cuya norma fundamental sería pacta sunt servanda ${ }^{25}$, nos planteamos la cuestión de la posible coordinación de los sistemas jurídicos constitucionales entrelazados en la UE, reconociéndose mutuamente su propia validez, pero reivindicando uno de ellos la primacía sobre los restantes, en el ámbito concreto de las competencias atribuidas. Sin embargo, los Tribunales Constitucionales de algunos Estados miembros como el alemán, el italiano, el danés, o el español se reservan la posibilidad de supervisar la compatibilidad de los actos comunitarios con sus propias constituciones, especialmente desde la perspectiva de los derechos fundamentales. Pues bien, con la entrada en vigor del Tratado de Lisboa el 1 de diciembre de 2009 y la consiguiente invocabilidad jurídica de la Carta de los Derechos Fundamentales de la Unión, pero sobre todo cuando se plasme la adhesión de la Unión Europea al Convenio Europeo de Derechos Humanos, nos encontraremos con una nueva situación donde la UE se someterá jurídicamente al control del Tribunal Europeo de Derechos Humanos que podrá declarar que ciertas medidas normativas o administrativas de la UE o incluso sentencias de su Tribunal de Justicia vulneran uno de los derechos reconocidos en el Convenio o en sus Protocolos.

Esta nueva situación parece cerrar el círculo de la protección de los derechos fundamentales en Europa, creándose de este modo una especie de unión o confederación, una red de sistemas de protección de los derechos fundamentales (Grundrechtsschutzverbund), que además resultan ser principios generales del Derecho, más allá de su concreta positividad convencional o constitucional. A diferencia del pluralismo en sentido estricto o pluralismo radical, en este pluralismo bajo el Derecho internacional no es necesario salirse fuera del Derecho hacia los dominios de la política para resolver los casos más difíciles donde parecen colisionar las normas de distintos sistemas. Los derechos fundamentales forman parte inherente del concepto interpretativo del Derecho. Se reintroduce un cierto monismo en esta red heterárquica de sistemas, una coherencia global, obtenida a través de una reconstrucción racional y «principial» del Derecho - pacta sunt servanda y derechos humanos- cercana a la noción de integridad de DwORKIN, pero no referida a la Constitución de EEUU sino a los derechos humanos universales. En esta concepción interpretativa-hermenéutica, focal, del Derecho aflora un cierto Derecho natural.

25 Questioning Sovereignty, pp. 108-121. 